I Instituto Brasiliense de Direito Público, Brasília, DF

e Insper, São Paulo, SP, Brasil

joaopbachur@hotmail.com

João Paulo Bachur'

\title{
A PRÁTICA DA TEORIA
}

Luhmann, Niklas. (20I8). Teoria dos sistemas na prática, v. I

(Estrutura social e semântica).

Edição de Leopoldo Waizbort. Tradução de Patrícia da Silva

Santos. Revisão técnica da tradução de Leopoldo Waizbort

e Guilherme Leite Gonçalves. Petrópolis: Vozes.

Há muito o que comemorar com a publicação desse livro de Niklas Luhmann no bojo da Coleção Sociologia, pela Editora Vozes. Primeiro de uma constrói, na sociedade, uma miniatura dela mesma, como uma autodescrição. A sociedade da sociedade é a descrição que a sociedade atual, funcionalmente diferenciada, faz de si mesma. Esse ponto culminante é o resultado de uma produção acadêmica vigorosa e longeva. Essa produção pode ser dividida em quatro eixos, elaborados de forma razoavelmente simultânea ao longo de mais de 30 anos, quais sejam: os primeiros escritos, os seis volumes de Soziologische Aufklärung ("Esclarecimento sociológico"), as monografias de sua teoria geral da sociedade e os estudos sobre estrutura social e semântica.

Os primeiros escritos, da década de I960 até I984 (ano de publicação de Sistemas sociais - marco da virada autopoiética de Luhmann), transitavam na sociologia jurídica e política e 
tinham por objeto temas como o procedimento, direitos fundamentais e o Estado de bem-estar. É desse período a célebre polêmica com Habermas, que difundiu Luhmann e sua teoria de sistemas como uma apologia tecnocrática do mundo administrado, pelo menos em um primeiro momento (Habermas \& Luhmann, I97I). Esse primeiro período pode ser considerado uma espécie de preâmbulo da teoria da sociedade que Luhmann passaria o restante da vida elaborando. Ainda não se tem então o conceito de autopoiese. Da mesma forma, o escopo de construir uma teoria geral da sociedade, se existia, não estava explicitamente apresentado, de sorte que podemos notar Luhmann intuitivamente progredindo nos ramos em que ele se sentia mais confortável - sociologia do direito, teoria das organizações e sociologia política. Talvez pudéssemos designar esse período como "pré-cibernético".

A coletânea Esclarecimento sociológico, por sua vez, marca a incorporação não apenas da cibernética, mas da miríade de influências heterodoxas que Luhmann absorveu progressivamente (cibernética, lógica das formas, construtivismo radical e a teoria geral de sistemas) para construir sua teoria sociológica. A coletânea é composta por seis volumes de artigos publicados entre ig62 e i994, e seu título expressa o programa teórico de Luhmann: a ideia de um esclarecimento radicalmente desencantado, capaz de descrever, na minúcia, o funcionamento da sociedade contemporânea. Vários problemas teóricos da teoria de sistemas, tais como a questão do primado funcional e da relação entre ação e comunicação, são ali trabalhados verticalmente.

As monografias compreendem os trabalhos publicados entre Sistemas sociais (1984) e A sociedade da sociedade (I997), quais sejam, monografias dedicadas à economia, à ciência, ao direito, à arte, aos meios de comunicação de massa, à política, à religião e à educação da sociedade (essas três últimas publicadas postumamente). Entre o chamado "capítulo zero", Sistemas sociais, e o fecho da teoria geral de Luhmann, A sociedade da sociedade, essas obras monográficas tratam intensivamente do conceito de autopoiese nos sistemas funcionais individualmente considerados.

Até aqui, portanto, o panorama é o de um labirinto conceitual - e a associação da teoria de sistemas de Luhmann à metáfora do labirinto tem-se tornado cada vez mais corriqueira. A bússola para orientar o leitor no percurso pelo labirinto pode ser encontrada nos estudos de estrutura social e semântica: os longos e densos ensaios reunidos nos quatro volumes de Gesellschaftsstruktur und Semantik. Studien zur Wissenssoziologie der modernen $\mathrm{Ge}$ sellschaft ("Estrutura social e semântica: estudos de sociologia do conhecimento na sociedade moderna"), publicados entre I980 e I995, acompanhados tematicamente de Liebe als Passion: zur Codierung von Intimität ("Amor como paixão: a codificação da intimidade") (I982) e do póstumo Ideenevolution ("Evolução das ideias") (2008).

O conceito de estrutura social não 
tem qualquer parentesco com o estruturalismo, ao mesmo tempo em que semântica não designa o campo linguístico do estudo dos signos. A diferença entre estrutura social e semântica está relacionada à diferença entre operação e observação (muito embora os estudos nesse eixo bibliográfico se tenham iniciado muito antes da incorporação dos conceitos de operação e observação por Luhmann a partir da lógica das formas, de George Spencer Brown). A estrutura social se refere ao nível operativo da reprodução dos elementos de um sistema e, com isso, da manutenção da fronteira sistema/ambiente pelo sistema. A semântica, por sua vez, está relacionada à observação das operações do sistema e à construção de fórmulas condensadas de sentido ajustadas para as descrever. A semântica, conceito apropriado da história conceitual (Begriffsgeshichte) de Reinhart Koselleck (I979), preserva esta inspiração original: expressar a mudança histórica por meio dos conceitos e da linguagem empregada para a descrever. Diferentemente de Koselleck, porém, a evolução sociocultural em Luhmann articula a dimensão semântica a uma dimensão estruturante subjacente (a estrutura social).

A semântica é, assim, o acervo cultural e conceitual da sociedade mobilizado em sua auto-observação e em sua autodescrição. O genial estudo de Luhmann (I989/I993) sobre a origem da propriedade privada, por exemplo, mostra como a transformação nas operações por meio das quais o solo podia ser apropriado ou dividido exigiu um conceito específico para isso. Há outro sentido para semântica: ela expressa a dimensão de sentido disponível para usos reiterados na comunicação da sociedade, que evolui de acordo com a evolução da estrutura da sociedade - de algo absurdo e improvável, a propriedade privada se afirma como algo corriqueiro e (aparentemente) trivial.

É por isso que os estudos de estrutura social e semântica fornecem a melhor extração da teoria de sistemas. Esses estudos, produzidos por Luhmann sem visar à publicação em periódicos ou à intervenção acadêmica, são em geral densos e longos, pois trabalham um conceito em profundidade. Não um conceito do léxico luhmanniano decorrente da incorporação da cibernética e de outras fontes heterodoxas (autopoiese, observação de segunda ordem, diferença entre identidade e diferença etc.): trata-se aqui de conceitos clássicos da tradição sociológica, tais como ordem social, classes sociais, propriedade privada, religião, ética e moral, individualismo e Estado, entre muitos outros.

Aqui, vemos a teoria de sistemas sociais "na prática", isto é, aplicada para dialogar com a tradição sociológica aprofundando o acervo conceitual disponível para aprimorar as descrições sociológicas mediante o estudo de "casos" históricos que se constituem em pontos cruciais da passagem à modernidade. Isso, aliás, mostra o acerto na escolha do título desse volume: por mais inusitado que possa parecer ao leitor que se aproxima de Luhmann, tem-se aqui justamente a 
teoria de sistemas posta em prática.

O primeiro texto, por exemplo, "Como é possível ordem social?", engaja a teoria de sistemas funcionalmente diferenciados na busca da pergunta fundante da sociologia. Em certo sentido, pode-se dizer que a episteme sociológica constitui-se em oferecer diagnósticos de longo prazo para a passagem à modernidade, relativizando o peso de Marx (racionalização para Weber, os aspectos morais da divisão do trabalho para Durkheim, a formalização e anonimização das formas de vida para Simmel, o processo civilizatório de Elias, a diferenciação social em Parsons, para ficarmos apenas com os exemplos canônicos). Ordem social só é possível com a construção de sistemas sociais. E, por isso, a melhor descrição de uma sociedade diferenciada funcionalmente por sistemas tem de ser a de uma teoria de sistemas.

Na sequência, tem-se "Sobre o conceito de classe social", texto seminal para compreendermos a estratégia pela qual Luhmann imuniza (ou tenta imunizar ${ }^{\mathrm{I}}$ ) o primado da diferenciação funcional de pressões estratificantes. Nesse texto, Luhmann argumenta que a sociedade funcionalmente diferenciada é a mais apta a conviver com a desigualdade social que ela própria produz, pois (segundo Luhmann) só à política interessa a comunicação política; ao direito, a comunicação estruturada pelo código lícito/ilícito; à arte, a comunicação estética; à ciência, a produção de novo conhecimento. Não interessa, para os sistemas, aspectos estratificantes. Esse texto é o embrião da forma inclusão/exclusão, que desencadeou importante polêmica na recepção da teoria de sistemas sociais.

Por fim, "Indivíduo, individualidade, individualismo" traz argumentos sólidos para sustentar que Luhmann é, em linha com a tradição sociológica, um individualista. Essa afirmação pode causar arrepios àqueles que estão habituados à afirmação segundo a qual, para a teoria de sistemas sociais, "não existem indivíduos". Há, nessa afirmação, um erro crasso. É claro que existem. Afinal, poderíamos levar Luhmann a sério se ele dissesse, efetivamente, que indivíduos não existem? O que ele afirma é que a sociedade não se compõe de indivíduos, como unidades últimas e irredutíveis do social, mas de interações; de comunicação funcionalmente diferenciada. A rigor, Luhmann argumenta que a diferenciação de sistemas autopoiéticos, ao eliminar aspectos estratificantes e funcionalizar a comunicação, amplia a liberdade dos indivíduos, que podem tomar parte em comunicações políticas, científicas, estéticas, econômicas e jurídicas de forma incongruente, sem que seu papel nesses sistemas seja unificado por uma noção agregadora (a classe social ou o estamento).

Por tudo isso, o leitor brasileiro passa a ter acesso ao melhor de Luhmann. Esses três textos só fazem aguçar a curiosidade pelos volumes que se seguirão. A teoria de sistemas, na prática, mostra muito mais que conceitos complicados. Mostra clareza na explicação histórica e na formulação conceitual para o diálogo com a tradição sociológica. A prática da teoria de sistema sociais é: oferecer descrições. Disponibili- 
zar e engrandecer o acervo conceitual da teoria sociológica com o escopo de aprimorar as autodescrições que a sociedade é capaz de oferecer. Aqui, o leitor brasileiro tem acesso à teoria posta em prática e a textos seminais para descrição da sociedade contemporânea como sociedade de sistemas funcionalmente diferenciados. Que venham os próximos volumes!

Recebida em 8/9/20I8 | Aprovada em I $7 / 9 / 2018$

João Paulo Bachur é graduado em direito (200I), mestre (2004) e doutor (2009) em ciência política pela USP; foi pesquisador visitante no Instituto de Filosofia da Universidade Livre de Berlim como bolsista da Fundação Alexander von Humboldt (20I 2-20I3). É professor na pós-graduação lato sensu do Instituto de Ensino e Pesquisa (Insper), São Paulo, e coordenador do mestrado em direito constitucional do Instituto Brasiliense de Direito Público, Brasília. Publicou, entre outros, Às portas do labirinto: para uma recepção crítica da teoria social de Niklas Luhmann (2010) e Schrift und Gesellschaft: Die Kraft der Inskriptionen in der Produktion des Sozialen (2016). 


\section{NOTA}

I "Tenta imunizar" porque há questionamentos por parte de alguns intérpretes quanto à efetividade dessa estratégia, ainda que esses questionamentos sejam minoritários. Ver Bachur (20I2) para uma resenha das principais polêmicas.

\section{REFERÊNCIAS BIBLIOGRÁFICAS}

Bachur, João Paulo. (2012). Inclusão e exclusão na teoria de sistemas sociais: um balanço crítico. Revista Brasileira de Informação Bibliográfica em Ciências Sociais - BIB, 73, p. 55-83.

Habermas, Jürgen \& Luhmann, Niklas. (I97I). Theorie der Gesellschaft oder Sozialtechnologie - was leistet die Systemforschung? Frankfurt: Suhrkamp.

Koselleck, Reinhart. (I979). Begriffsgeschichte und Sozialgeschichte. In: Koselleck, Reinhart (org.). Historische Semantik und Begriffsgeschichte. Stuttgart: Klett-Cotta, p. 19-36.

Luhmann, Niklas. (I993) [I989]. Am Anfang war kein Unrecht. In: Gesellschaftsstruktur und Semantik. Studien zur Wissenssoziologie der modernen Gesellschaft, 3. Frankfurt: Suhrkamp, p. I I-64. 